\title{
Response to Viewpoint: Whither Problem Structuring Methods (PSMs)?
}

We readily agree that Problem Structuring Methods are "very relevant in today's world" and that it follows that in addition to their application in practice they should be a focus for research and for teaching.

We also agree that the underrepresentation of these methods in JORS is a cause for concern, not least because for many practitioners this is the only journal that they have access to via their subscriptions to the OR Society. In fact, one of the motivating factors for our publishing in JORS was to make a contribution to countering this underrepresentation. We were, and remain, keen to highlight to both researchers and practitioners that there is much for to learn from reflecting upon the application of PSMs to real world problems and we appreciate the similar contribution from Abuabara, Paucar-Caceres, Belderrain, and Burrowes-Cromwell (2017). We find that PSMs are now mainstream and so of at least as much interest to practitioners as researchers.

Our paper (Lowe, Martingale, \& Yearworth, 2016) described how the mixing of methods was important to meeting the needs of specific situation and offered some reflections from our practice, that we judged to likely to be transferrable to other situations. We highlighted how we believed our work contributed to the research agenda set down by Ackermann, Franco, Rouwette, and White (2014) in the preface to a special issue on problem structuring research and practice published in the EURO Journal on Decision Processes. We also identified some areas for future research ourselves.

Our answer to the question: "Have PSMs run their course?" raised above then is clearly not. In further support of this position we would highlight a number of relatively recent papers published in JORS of relevance to PSM practice that were not mentioned - (Bell \& Morse, 2013; Kotiadis, Tako, \& Vasilakis, 2014; Lane, 2016; Ormerod, 2014; Powell \& Mustafee, 2017; Smith \& Shaw, 2018; Tavella \& Papadopoulos, 2015) - and suggest that the remark that "PSMs are off (sic) interest to fewer and fewer researchers" based on evidence from JORS should perhaps be reinterpreted. Searching more widely, Figure 1 shows the document count by year returned by the Scopus search TITLE-ABS-KEY ("problem structuring method*") up to and including 2017. The cumulative citation count for the total of 195 articles is 2871. We would also highlight the survey work of Ranyard, Fildes, and $\mathrm{Hu}$ (2015). 


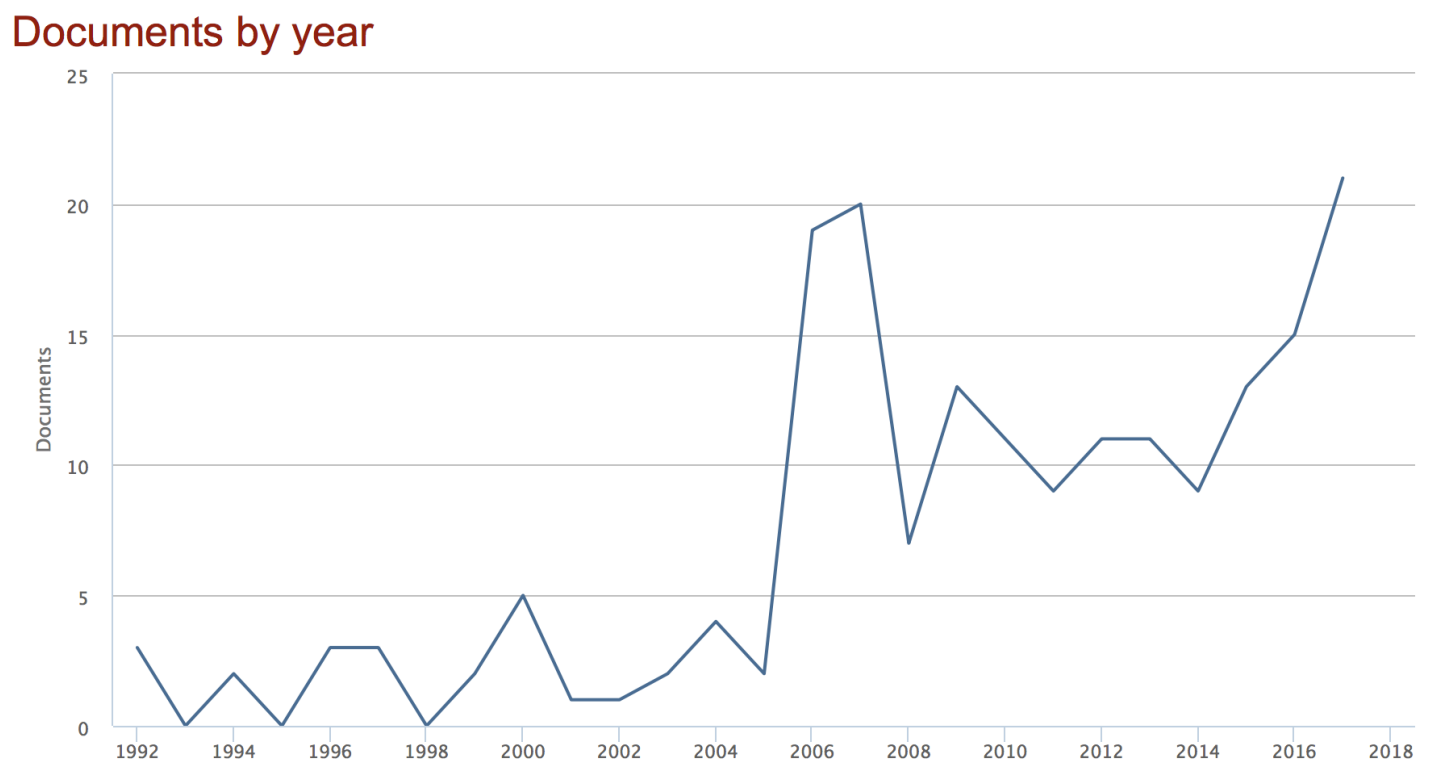

Figure 1. Document count by year returned by the Scopus search ("problem structuring method*")

Our answer to the question: "Has there been a renaming of PSMs?" is less categorical. Whilst PSMs publication rates are increasing (as evidenced Figure 1), it is also true that an increasing focus for PSM research relates to the interplay between the participants involved and so often features under the headings of Group Decision and Negotiation (GDN) - see for example: Tavella and Franco (2015) and Ackermann, Eden, and Pyrko (2016), or the behavioural turn in OR - see for example Franco and Hamalainen (2016) and White (2016). Behavioural OR in particular is a growth area as evidenced by strengthening streams at recent EURO and IFORS conferences, the creation of a Behavioural OR special interest group sponsored by the OR Society, and the launch of a Behavioural OR website portal. There is a Special Issue on microprocesses of group decision and negotiation due to appear in the journal Group Decision and Negotiation later in 2018.

Our answer to the question "Where is the research to develop a deeper understanding of PSMs?" is somewhat awkward given where are publishing this response. We see that much of the current debate about the development of PSMs is taking place in the European Journal of Operational Research. This is partly due to the inexorable pressure of the Research Excellence Framework (REF) on UK based researchers to target higher ranking journals ${ }^{1}$ but also because there have been two recent special issues - on Behavioural OR and Community OR - that have attracted the contributions from a number of researchers active in PSM development. One of us (Yearworth) has been rather more active in EJOR than in JORS for these two

\footnotetext{
${ }^{1}$ Checkland (2006) remarked on the 'baleful influence' on practice of the Research Assessment Exercise (the predecessor to the REF) more than 10 years ago.
} 
reasons (White, Burger, \& Yearworth, 2016; Yearworth \& White, 2014; Yearworth \& White, 2018).

Perhaps now is the time for JORS to revisit the subject with a Special Issue on PSMs? Ten years or so strikes us as an appropriate interval over which to reflect upon how the field has changed.

\section{References}

Abuabara, L., Paucar-Caceres, A., Belderrain, M.C.N., \& Burrowes-Cromwell, T. (2017). A systemic framework based on Soft OR approaches to support teamwork strategy: an aviation manufacturer Brazilian company case. Journal of the Operational Research Society. doi: 10.1057/s41274-0170204-9

Ackermann, F., Eden, C., \& Pyrko, I. (2016). Accelerated Multi-Organization Conflict Resolution. Group Decision and Negotiation, 1-22.

Ackermann, F., Franco, L.A., Rouwette, E., \& White, L. (2014). Problem structuring research and practice for the next decade: looking back to go forward. EURO Journal on Decision Processes, 2(3-4), 165-172. doi: DOI 10.1007/s40070-014-0037-6

Bell, S., \& Morse, S. (2013). Groups and facilitators within problem structuring processes. Journal of the Operational Research Society, 64(7), 959-972. doi: 10.1057/jors.2012.110

Checkland, P. (2006). Reply to Eden and Ackermann: Any future for problem structuring methods? Journal of the Operational Research Society, 57(7), 769-771. doi: 10.1057/palgrave.jors.2602111

Franco, L.A., \& Hamalainen, R.P. (2016). Behavioural operational research: Returning to the roots of the OR profession. European Journal of Operational Research, 249(3), 791-795. doi: 10.1016/j.ejor.2015.10.034

Kotiadis, K., Tako, A.A., \& Vasilakis, C. (2014). A participative and facilitative conceptual modelling framework for discrete event simulation studies in healthcare. Journal of the Operational Research Society, 65(2), 197-213. doi: 10.1057/jors.2012.176

Lane, D.C. (2016). What we talk about when we talk about 'systems thinking'. Journal of the Operational Research Society, 67(3), 527-528. doi: 10.1057/jors.2015.10

Lowe, D., Martingale, L., \& Yearworth, M. (2016). Guiding interventions in a multi-organisational context: combining the Viable System Model and Hierarchical Process Modelling for use as a Problem Structuring Method. Journal of the Operational Research Society. doi: 10.1057 jors.2016.6

Ormerod, R.J. (2014). The mangle of OR practice: Towards more informative case studies of 'technical' projects. Journal of the Operational Research Society, 65(8), 1245-1260. doi: $10.1057 /$ jors. 2013.78 
Powell, J.H., \& Mustafee, N. (2017). Widening requirements capture with soft methods: An investigation of hybrid M\&S studies in health care. Journal of the Operational Research Society, 68(10), 1211 1222. doi: 10.1057/s41274-016-0147-6

Ranyard, J.C., Fildes, R., \& Hu, T.-I. (2015). Reassessing the scope of OR practice: The Influences of Problem Structuring Methods and the Analytics Movement. European Journal of Operational Research, 245(1), 1-13. doi: 10.1016/j.ejor.2015.01.058

Smith, C.M., \& Shaw, D. (2018). Horizontal recursion in soft OR. Journal of the Operational Research Society, 1-14. doi: 10.1080/01605682.2017.1421847

Tavella, E., \& Franco, L.A. (2015). Dynamics of Group Knowledge Production in Facilitated Modelling Workshops: An Exploratory Study. Group Decision and Negotiation, 24(3), 451-475. doi: 10.1007/s10726-014-9398-2

Tavella, E., \& Papadopoulos, T. (2015). Expert and novice facilitated modelling: A case of a Viable System Model workshop in a local food network. Journal of the Operational Research Society, 66(2), 247-264. doi: 10.1057/jors.2013.187

White, L. (2016). Behavioural operational research: Towards a framework for understanding behaviour in OR interventions. European Journal of Operational Research, 249(3), 827-841. doi: 10.1016/j.ejor.2015.07.032

White, L., Burger, K., \& Yearworth, M. (2016). Understanding behaviour in problem structuring methods interventions with activity theory. European Journal of Operational Research, 249(3), 983-1004. doi: 10.1016/j.ejor.2015.07.044

Yearworth, M., \& White, L. (2014). The non-codified use of problem structuring methods and the need for a generic constitutive definition. European Journal of Operational Research, 237(3), 932-945. doi: 10.1016/j.ejor.2014.02.015

Yearworth, M., \& White, L. (2018). Spontaneous emergence of Community OR: self-initiating, selforganising problem structuring mediated by social media. European Journal of Operational Research. doi: 10.1016/j.ejor.2018.01.024 